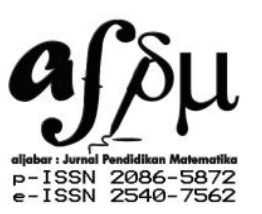

Al-Jabar: Jurnal Pendidikan Matematika

Vol. 7, No. 2, 2016, Hal 221 - 230

\title{
Aktivitas Matematika Berbasis Budaya pada Masyarakat Lampung
}

\section{Rosida Rakhmawati M.}

IAIN Raden Intan Lampung: Email: oci_rosida@yahoo.com

\begin{abstract}
Math-based culture called ethnomatematics is an approach that can be used to explain the role of mathematics in a multicultural society. Mathematical concepts used to explore the existence of mathematics in culture, especially traditional societies of Lampung. This study aims to describe the results of exploration Lampung ethnomatematics with this kind of exploratory research as well as an ethnographic approach. The results showed that without studying the mathematical concept, traditional society of Lampung have applied these concepts in their daily lives using ethnomatematics. Proved the existence of mathematical concepts contained in custom home building, the local unit of Lampung, geometric shapes motif of tapis, as well as traditional games Lampung. Researchers suggest the results of this study to: (a) used as alternative ideas mathematics learning outside the classroom, (b) introduced in learning formal mathematics as initial capital to teach the concept of mathematics to students, (c) be used as reference material for preparing a matter of mathematical problem solving context.
\end{abstract}

Keywords: Mathematics, Ethnomathematics, culture.

\begin{abstract}
Abstrak
Matematika berbasis budaya yang sering disebut etnomatematika merupakan sebuah pendekatan yang dapat digunakan untuk menjelaskan peran matematika dalam masyarakat multibudaya. Konsep matematika digunakan untuk mengeksplorasi keberadaan matematika dalam budaya khususnya masyarakat tradisional lampung Penelitian ini bertujuan mendeskripsikan hasil eksplorasi etnomatematika masyarakat lampung dengan jenis penelitian eksplorasi serta pendekatan etnografi. Hasil penelitian menunjukkan bahwa tanpa mempelajari konsep matematika, masyarakat Lampung telah menerapkan konsepkonsep tersebut dalam kehidupan sehari-harinya menggunakan etnomatematika. Terbukti adanya konsep-konsep matematika yang terkandung dalam bangunan rumah adat, satuan lokal masyarakat Lampung, bentuk geometri motif kain tapis, serta permainan tradisional masyarakat Lampung. Peneliti menyarankan hasil penelitian ini untuk: (a) dijadikan ide alternatif pembelajaran matematika di luar kelas, (b) dikenalkan pada pembelajaran matematika formal sebagai modal awal mengajarkan konsep matematika kepada siswa, (c) dijadikan bahan rujukan untuk menyusun soal pemecahan masalah matematika kontekstual.
\end{abstract}

Kata Kunci: Matematika, Etnomatematika, budaya.

\section{PENDAHULUAN}

Pengetahuan matematika tidak hanya dapat diperoleh dari sistem terstruktur pembelajaran matematika seperti sekolah, tetapi dapat diperoleh dari luar sekolah, 
pendidik harus mengupayakan berbagai alternatif dan inovasi dalam rangka meningkatkan kemampuan matematika siswa. Salah satu kuncinya adalah perbaikan proses pembelajaran di sekolah, khususnya dengan meningkatan porsi menalar, memecahkan masalah, berargumentasi dan berkomunikasi melalui materi ajar yang lebih kontekstual yang dapat diterapkan dengan pendidikan berbasis budaya. Pembelajaran berbasis budaya merupakan strategi penciptaan lingkungan belajar dan perancangan pengalaman belajar yang mengintegrasikan budaya sebagai bagian dari proses pembelajaran. (Muzakki \& Fauziah, 2015)

Etnomatematika dipersepsikan sebagai lensa untuk memandang dan memahami matematika sebagai produk budaya (Puspadewi \& Gst. Ngurah Nila Putra, 2014) Aktivitas Matematika Berbasis Budaya Pada Masyarakat Lampung dinilai penting sebagai suatu kajian khusus tentang matematika yang dimiliki dan dipraktikkan oleh masyarakat Lampung secara turun temurun, yang diharapkan dapat menjadi bahan rujukan pembelajaran matematika kontekstual. Pembelajaran ini merupakan salah satu cara yang dipersepsikan dapat menjadikan pembelajaran matematika bermakna dan kontekstual yang diyakini dapat menstimulasi anak untuk menggunakan kemampuan berpikirnya yang melahirkan pembelajaran yang kaya dan reflektif. Konteks budaya digunakan untuk merangsang petualangan anak karena mudah diingat, anak terlibat langsung di dalamnya dan berhubungan langsung dengan kehidupan sehari-hari anak. (Eti Rohaeti, 2011)

Berdasarkan penelitian terdahulu, telah dilakukan beberapa penelitian mengenai pembelajaran berbasis budaya yang digunakan dalam rangka meningkatkan mutu pendidikan, mengintegrasikan nilai nilai budaya dalam pembelajaran, mengembangkan model model pendidikan dengan nilai-nilai budaya, serta mentransformasikan budaya melalui pembelajaran matematika (Eti Rohaeti, 2011; Kania, Kartimi, \& Mulyani, 2013; Muzakki \& Fauziah, 2015; Qolbi, Kartimi, \& Roviati, 2016; Sariyatun, 2013; Supriadi, Arisetyawan, \& Tiurlina, 2016; Tanu, 2016) Namun, dalam penelitian sebelumnya belum ada penelitian yang mendeskripsikan aktivitas etnomatematika pada Budaya Lokal Masyarakat Lampung.

Berdasarkan penelitian yang telah dilakukan sebelumnya, keterbaruan dalam penelitian ini terletak pada bagaimana bentuk aktivitas etnomatematika pada budaya lokal masyarakat yang ada di Lampung. Maka, tujuan dari penelitian ini adalah mendeskripsikan hasil aktivitas Etnomatematika pada Budaya Lokal Masyarakat Lampung dan mendokumentasikan budaya masyarakat Lampung berkaitan dengan matematika agar tidak hilang.

\section{METODE PENELITIAN}

Penelitian ini termasuk dalam jenis penelitian eksploratif, merupakan penelitian penggalian, menggali untuk menemukan dan mengetahui suatu gejala atau peristiwa 
(konsep atau masalah) dengan melakukan penjajakan terhadap gejala tersebut, sedangkan pendekatan yang digunakan dalam penelitian ini adalah pendekatan etnografi yaitu pendekatan empiris dan teoritis yang bertujuan mendapatkan deskripsi dan analisis mendalam tentang kebudayaan berdasarkan penelitian lapangan (fieldwork) yang intensif. Pendekatan ini memusatkan usaha untuk menemukan bagaimana masyarakat mengorganisasikan budaya mereka dalam pikiran mereka dan kemudian menggunakan budaya tersebut dalam kehidupan, budaya tersebut ada dalam pikiran manusia. Tugas etnograf adalah menemukan dan menggambarkan organisasi pikiran tersebut.

Sehubungan dengan penelitian ini, peneliti berusaha menggali informasi melalui kepustakaan, pengamatan (observasi) serta proses wawancara dengan beberapa tokoh atau warga masyarakat lampung yang mengetahui informasi mengenai objek yang akan digali. Penelitian ini bertujuan mendeskripsikan hasil eksplorasi bentuk etnomatematika masyarakat lampung berupa konsep-konsep matematika pada berbagai peninggalan budaya yang masih ada di Lampung. Secara garis besar prosedur penelitian yang akan dilakukan pada penelitian ini sesuai dengan prosedur penelitian yang mengadopsi pendekatan etnografis, memuat:

\section{Menetapkan Informan}

Informan yang baik adalah informan yang terlibat langsung serta mengetahui secara baik tentang hal yang akan dikaji. Informan yang dipilih dalam penelitian ini adalah orangorang yang dianggap dapat bercerita secara mudah, serta paham terhadap informasi yang dibutuhkan.

\section{Melakukan Wawancara terhadap Informan}

Ada beberapa etika yang harus dipatuhi pewawancara, antara lain mempertimbangkan kepentingan informan terlebih dahulu, menyampaikan tujuan penelitian, melindungi privasi informan, dan jangan mengeksploitasi informan.

\section{Membuat Catatan Etnografis}

Sebuah catatan etnografis meliputi catatan lapangan, alat perekam gambar, artefak dan benda lain yang mendokumentasikan suasana budaya yang dipelajari.

\section{Mengajukan Pertanyaan Deskriptif}

Pertanyaan deskriptif merupakan pertanyaan yang membutuhkan jawaban penjelas.

\section{Melakukan Analisis Wawancara Etnografis}

Analisis wawancara menggaris bawahi semua istilah asli informan yang telah diperoleh untuk mempertinggi peranannya dalam mengetahui tentang obyek budaya yang diteliti. Analisis ini dikaitkan dengan simbol dan makna yang disampaikan informan.

\section{Membuat Analisis Domain}

Peneliti membuat istilah mencakup dari apa yang dinyatakan informan dengan membuat hubungan semantis yang jelas. 


\section{Mengajukan Pertanyaan Struktural}

Pertanyaan struktural merupakan pertanyaan yang disesuaikan dengan informan. Pertanyaan struktural bertujuan mengetahui bagaimana informan mengorganisir pengetahuan mereka.

\section{Melakukan Analisis Taksonomi}

Analisis taksonomi memusatkan perhatian pada domain tertentu yang sangat berguna untuk menggambarkan fenomena atau masalah yang menjadi sasaran penelitian. Analisis taksonomik dilakukan untuk membuat kategori dari simbol-simbol budaya yang ada pada kebudayaan yang diteliti.

\section{Menulis etnografi}

Peneliti kemudian memberikan penjelasan secara naratif mengenai esensi dari temuannya yang diteliti dan mendapat makna pengalaman informan.

\section{HASIL DAN PEMBAHASAN}

Etnomatematika dipersepsikan sebagai lensa untuk memandang dan memahami matematika sebagai produk budaya. Budaya yang dimaksud disini mengacu pada bahasa masyarakat, tempat, tradisi, cara mengorganisir, menafsirkan, konseptualisasi, dan memberikan makna terhadap dunia fisik dan sosial. (Puspadewi \& Gst. Ngurah Nila Putra, 2014) Etnomatematika sebagai cara-cara khusus yang dipakai oleh suatu kelompok budaya atau masyarakat tertentu dalam aktivitas matematika. Di mana aktivitas matematika adalah aktivitas yang di dalamnya terjadi proses pengabstraksian dari pengalaman nyata dalam kehidupan sehari-hari ke dalam matematika atau sebaliknya, meliputi aktivitas mengelompokkan, berhitung, mengukur, merancang bangunan atau alat, membuat pola, membilang, menentukan lokasi, bermain, menjelaskan, dan sebagainya. Sedangkan bentuk etnomatematika adalah berbagai hasil aktivitas matematika yang dimiliki atau berkembang di masyarakat Lampung, meliputi konsep-konsep matematika pada peninggalan budaya berupa peralatan tradisional, satuan lokal, motif kain tapis, serta permainan tradisional.

Pertumbuhan dan perkembangan matematika terjadi karena adanya tantangan hidup yang dihadapi manusia di berbagai wilayah dengan berbagai latar belakang budaya yang berbeda. Setiap budaya dan sub-budaya mengembangkan matematika dengan cara mereka sendiri. Sehingga matematika dipandang sebagai hasil akal budi atau pikiran manusia dalam aktivitas masyarakat sehari-hari. Hal ini meyimpulkan bahwa matematika merupakan produk budaya hasil abstraksi pikiran manusia, serta alat pemecahan masalah.

Istilah ethnomathematics yang selanjutnya disebut etnomatematika diperkenalkan oleh D'Ambrosio, seorang matematikawan Brasil pada tahun 1977. (Puspadewi \& Gst. Ngurah Nila Putra, 2014) Urbiratan D’Ambrosio adalah seorang ahli pendidikan matematika yang menolak bahwa matematika bukanlah sesuatu yang bebas budaya dan bebas nilai. Matematika telah menyatu, dipraktikkan dan menjadi tradisi dalam seluruh aspek 
kehidupan masyarakat budaya. Penelitian pendidikan matematika yang sudah ada umumnya lebih terfokus pada ruang kelas. Namun, terdapat temuan baru yang menunjukkan bahwa banyak pengetahuan matematika yang juga dapat diperoleh di luar sekolah, salah satunya temuan tentang etnomatematika.

Siswa mengembangkan representasi dan prosedur ke dalam sistem kognitif mereka, yang merupakan proses yang terjadi dalam konteks kegiatan sosial yang dibangun.(Rosa \& Orey, 2011) Dengan kata lain, kemampuan belajar matematika siswa di sekolah tidak logis dibangun berdasarkan struktur kognitif abstrak melainkan ditempa dari kombinasi pengetahuan yang diperoleh sebelumnya dan keterampilan dan masukan budaya baru. Oleh karena itu, D'Ambrosio menegaskan bahwa matematika muncul dari kebutuhan masyarakat yang terorganisir, yang tidak dapat dipisahkan dari kegiatan dan praktik yang dikembangkan oleh orang-orang dalam masyarakat global. Istilah Etnomathematika ini diciptakan oleh D'Ambrosio tahun 1985 untuk menggambarkan praktek matematika pada kelompok budaya yang dapat diidentifikasi dan dianggap sebagai studi tentang matematika yang ditemukan di setiap kebudayaan. D'Ambrosio mendefinisikan ethnomathematika sebagai berikut:

"The prefix ethno is today accepted as a very broad term that refers to the socialcultural context and therefore includes language, jargon, and codes of behavior, myths, and symbols. The derivation of mathema is difficult, but tends to mean to explain, to know, to understand, and to do activities such as ciphering, measuring, classifying, inferring, and modeling. The suffix tics is derived from techné, and has the same root as technique "(p. 81).

Dengan kata lain, etno mengacu pada anggota kelompok dalam lingkungan budaya yang diidentifikasi oleh tradisi budaya, kode, simbol, mitos, dan cara-cara khusus mereka digunakan untuk alasan dan untuk menyimpulkan.

Pengajaran matematika bagi setiap orang seharusnya disesuaikan dengan budayanya. Untuk itu diperlukan suatu jembatan yang menghubungkan antara matematika di luar sekolah dengan matematika di dalam sekolah. Pada dasarnya peserta didik, telah memiliki pengetahuan awal (konsep awal) yang diperoleh dari lingkungan sosial budayanya. Hanya saja pengetahuan tersebut masih perlu digali, dibangun dan dikembangkan selama proses belajar mengajar, sehingga menghasilkan pengetahuan baru yang lebih aktual. Sedangkan memahami konsep awal peserta didik merupakan kegiatan yang tidak mudah, karena konsep awal peserta didik bersifat individual. Namun, jika guru tidak memperhatikan konsep awal tersebut akan berakibat munculnya kesulitan belajar.

Menurut Hilman Hadikusuma, Lampung adalah daerah dan kelompok etnik yang menggunakan bahasa Lampung. Secara adat, yang termasuk masyarakat Lampung tidak sebatas yang berada di Propinsi Lampung, tetapi juga masyarakat di daerah Danau Ranau, Muaradua, Komering, hingga Kayu Agung Propinsi Sumatera Selatan. 


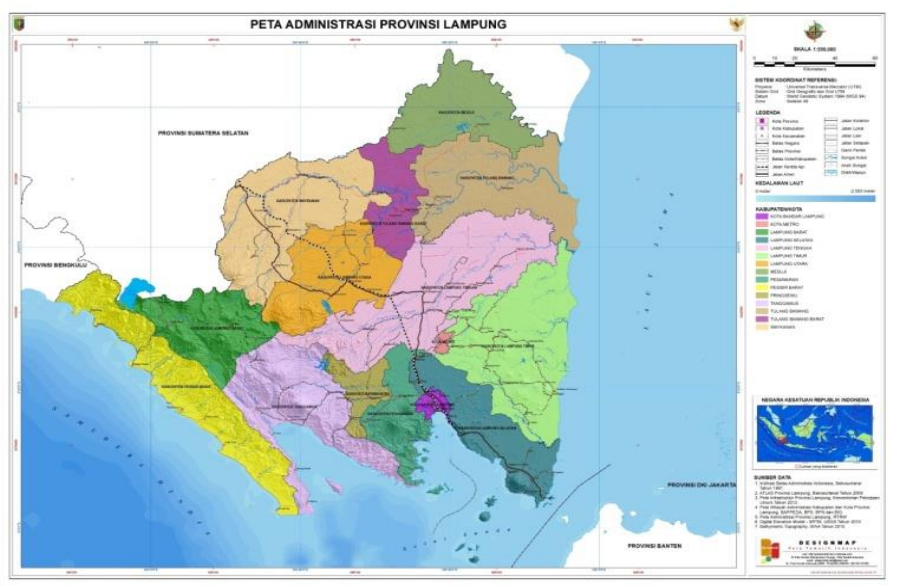

Gambar 1. Peta Provinsi Lampung

Lampung adalah sebuah provinsi paling selatan di Pulau Sumatera, Indonesia, Ibukotanya terletak di Bandar Lampung. sebelah utara berbatasan dengan Bengkulu dan Sumatera Selatan. Provinsi Lampung memiliki luas $35.376,50 \mathrm{~km}^{2}$ dan terletak di antara $105^{\circ} 45^{\prime}-103^{\circ} 48^{\prime}$ BT dan $3^{\circ} 45^{\prime}-6^{\circ} 45^{\prime}$ LS. Daerah ini di sebelah barat berbatasan dengan Selat Sunda dan di sebelah timur dengan Laut Jawa. Beberapa pulau termasuk dalam wilayah Provinsi Lampung, yang sebagian besar terletak di Teluk Lampung, di antaranya: Pulau Darot, Pulau Legundi, Pulau Tegal, Pulau Sebuku, Pulau Ketagian, Pulau Sebesi, Pulau Poahawang, Pulau Krakatau, Pulau Putus dan Pulau Tabuan. Ada juga Pulau Tampang dan Pulau Pisang di yang masuk ke wilayah Kabupaten Lampung Barat. Keadaan alam Lampung, di sebelah barat dan selatan, di sepanjang pantai merupakan daerah yang berbukit-bukit sebagai sambungan dari jalur Bukit Barisan di PulauSumatera. Di tengahtengah merupakan dataran rendah. Sedangkan ke dekat pantai di sebelah timur, di sepanjang tepi Laut Jawa terus ke utara, merupakan perairan yang luas. Masyarakat pesisir lampung mayoritas nelayan, dan bercocok tanam. Sedangkan masyarakat tengah sebagian besar berkebun lada, kopi, cengkeh, kayu manis dll.

Propinsi Lampung fokus pada pengembangan lahan bagi perkebunan besar seperti kelapa sawit, karet, padi, singkong, kakao, lada hitam, kopi, jagung, tebu dll. Beberapa daerah pesisir memiliki komoditas perikanan seperti tambak udang yang menonjol, bahkan untuk tingkat nasional dan internasional. Selain itu Lampung juga merupakan kota pelabuhan karena lampung adalah pintu gerbang untuk masuk ke pulau sumatra, dari hasil bumi yang melimpah tumbuhlah banyak industri-industri seperti di daerah pesisir panjang, daerah natar, tanjung bintang dan bandar jaya.

Berdasarkan hasil analisis domain, maka bentuk etnomatematika masyarakat Lampung berupa aktivitas matematika yang berkembang di masyarakat Lampung, meliputi konsep-konsep matematika dapat dikelompokkan pada peninggalan budaya (1) rumah adat/rancang bangun (2) satuan lokal, (3) motif kain tapis, (4) permainan tradisional. 


\section{1). Rumah Adat}

Konsep matematika sebagai hasil aktivitas merancang bangunan, mengukur, membuat pola, serta berhitung dapat diungkap dari pembuatan rumah adat. Konsep matematika dalam pembangunan, meskipun masyarakat lampung jaman dahulu belum mengenal materi dasar konstruksi bangunan seperti halnya yang sekarang diajarkan pada pendidikan formal (seperti konsep siku-siku, simetris, persegipanjang, maupun yang konsep geometri lain), tetapi mereka dapat membangun bangunan yang megah dan tahan lama jika dibandingkan dengan bangunan jaman sekarang. Mereka hanya melakukannya secara mengalir, menggunakan perkiraan dan satuan lokal (karena satuan SI belum dikenal pada saat itu), dan menerapkannya pada tata cara.

Konsep matematika sebagai produk. Masyarakat Lampung telah mengimplementasikan salah satu ilmu matematika yaitu Geometri dalam pembangunan bagian-bagian bangunan rumha adat diantaranya model bangun datar, meliputi persegi, persegipanjang, trapesium, segitiga, segitiga samakaki, segitiga samasisi, segilima, serta belah ketupat, model bangun ruang, meliputi kubus dan balok, model sifat matematis, meliputi sifat simetris, dan konsep translasi (pergeseran), serta pola dilatasi persegi pada bagian dalam atap rumah.

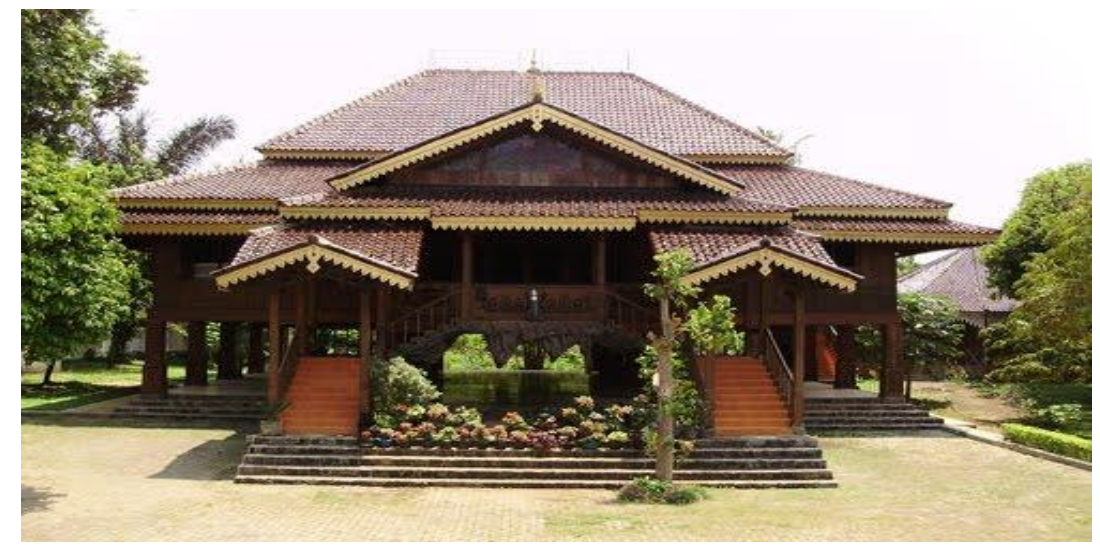

Gambar 2. Rumah adat Lampung

\section{2). Satuan Lokal}

Konsep matematika sebagai hasil aktivitas mengelompokkan, menghitung, serta menakar untuk menyelesaikan permasalahan dalam kehidupan sehari-hari sekaligus mempermudah masyarakat dalam melakukan aktivitas hariannya, Membilang berkaitan dengan pertanyaan "Berapa"atau dalam bahasa Lampung "Pigha". Membilang merupakan salah satu aktivitas yang sering dilakukan masyarakat. Bagi anak-anak pemula yang masih berada dalam tahap berpikir konkrit atau bagi komunitas masyarakat tradisional, untuk membilang mereka memerlukan alat-alat bantu. Berbagai jenis alat bantu yang sering digunakan antara lain: jari tangan dan batu. 
Tabel 1. Penyimbolan Bilangan 1-10 Masyarakat Lampung

\begin{tabular}{|c|c|}
\hline Angka arab & $\begin{array}{llllllllll}0 & 1 & 2 & 3 & 4 & 5 & 6 & 7 & 8 & 9\end{array}$ \\
\hline Aksara Lampung & $\neg-1$ \\
\hline
\end{tabular}

Pengukuran merupakan penentuan besaran, dimensi, atau kapasitas, biasanya terhadap suatu standar atau satuan pengukuran. Mengukur merupakan aktivitas yang biasa dilakukan dalam proses jual beli atau barter, rancang bangun, menentukan tinggi, panjang, keliling, luas, kedalaman, kecepatan dan sebagainya. Pengukuran yang dilakukan oleh masyarakat lampung pada jaman dulu menggunakan alat-alat ukur yang tidak baku seperti penggunaan anggota badan seperti tangan, depa, jengkal atau menggunakan alat ukur berupa barang-barang yang tersedia atau buatan seperti potongan kayu untuk mengukur panjang, dan kaleng untuk mengukur volume. Satuan pengukuran yaitu ukuran dari suatu besaran yang digunakan dalam pengukuran menyesuaikan dengan alat ukurnya, misalnya satuan depa, hasta, jengkal, kaki, kaleng, dan sebagainya.

Aktivitas mengukur juga terdapat pada pembangunan rumah adat, dalam menentukan tinggi tiang, panjang papan dan balok pada konstruksi bangunan yang dibutuhkan, mengukur kedalaman pondasi rumah adat, dan kebutuhan pembangunan lainnya

\section{3). Motif Kain Tapis}

Pada pembuatan tapis aktivitas membilang dilakukan ketika si pengrajin menghitung pola sulaman pada tapis, seperti hitungan 1 1, 2 2, dan 33 , rata-rata pengrajin jika membuat tapis dengan motif tertentu kebanyakan yang digunakan adalah pola 22 , maksudnya dalam proses membenamkan benang kedalam kain dasar tapis.

Konsep matematika sebagai hasil aktivitas memola yang dapat diungkap dari motif tapis dan bordir Lampung diantaranya konsep lingkaran, garis lurus dan garis lengkung, simetris, refleksi, dilatasi, translasi, serta rotasi. Terdapat kaidah-kaidah ilmu matematika yang terkandung dalam sulam tapis, seperti kedudukan titik, garis lurus, dan sudut yang dibentuk dari setiap proses penyulamannya. Dengan menerapkan konsep matematis pada teknik pengulangan, kain tapis tradisional maupun motif kain bordir itu bisa dikembangkan dan dimodifikasi.

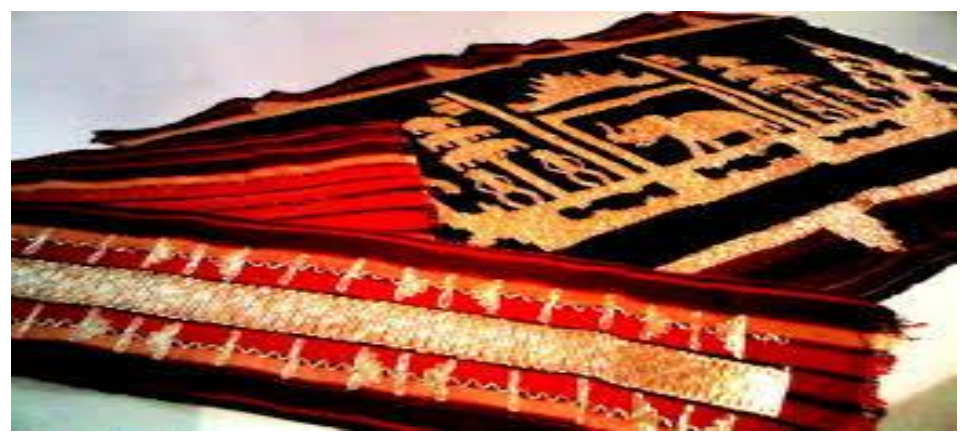

Gambar 3. Corak kain tapis 


\section{4). Permainan Tradisional}

Konsep matematika sebagai hasil aktivitas bermain berkaitan dengan aktivitas mengelompokkan, menghitung atau membilang. Masing-masing permainan tradisional masyarakat Lampung memiliki Konsep sebagai berikut :

a. Min Sundung Khulah : Konsep Peluang

b. Bedil Locok : Konsep Peluang

c. Babetes : Konsep pengenalan jarak dan waktu

d. Suksuk : Konsep geometri persegi, persegi panjang, trapesium dan jajar genjang

e. Bandar Karet: konsep peluang dan deret aritmatika

f. Gambaran : Konsep peluang dan deret aritmatika
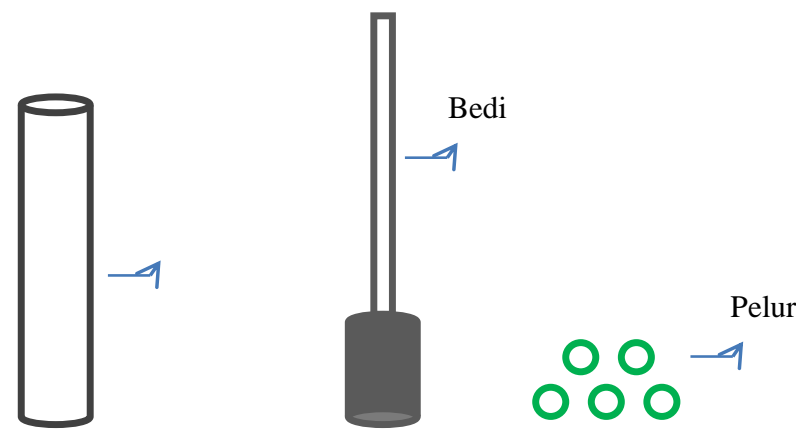

\section{Gambar 4.Perlengkapan Permainan Bedil Locok}

\section{SIMPULAN DAN SARAN}

Berdasarkan pembahasan yang telah dipaparkan pada bab sebelumnya, hasil penelitian menunjukkan bahwa terdapat cara-cara yang khusus pada masyarakat Lampung dalam melakukan aktivitas matematika. Tanpa mempelajari teori tentang konsep-konsep matematika, masyarakat Lampung pun telah menerapkan konsep-konsep matematika dalam kehidupan sehari-harinya menggunakan etnomatematika. Terbukti adanya bentuk etnomatematika masyarakat Lampung yang tercermin melalui berbagai hasil aktivitas matematika yang dimiliki dan berkembang di masyarakat Lampung, meliputi konsepkonsep matematika pada (1) Aktivitas membuat rancang bangun masyarakat menerapkannya pada pembangunan rumah adat (2) Satuan lokal yang dipraktekan masyarakat Lampung (3) Konsep matematika sebagai hasil aktivitas memola yang dapat diungkap dari motif tapis dan border (4) Aktivitas bermain terdapat tujuh permainan tradisional yang menggunakan konsep matematis seperti permainan sundung khulah, bedil locok, babetes, suksuk, bandarkaret, gambaran dan batu acak, yang dimainkan oleh anakanak. 
Berdasarkan kesimpulan penelitian ini, dapat diajukan beberapa saran bagi peneliti selanjutnya, diharapkan dapat mengkaji aktivitas-aktivitas matematika yang terdapat pada budaya budaya yang ada, yaitu selain budaya Lampung yang tentunya akan menambah wawasan mengenai etnomatematika.

\section{DAFTAR PUSTAKA}

Eti Rohaeti, E. (2011). Transformasi Budaya Melalui Pembelajaran Matematika Bermakna di Sekolah. Jurnal Pengajaran MIPA, 16(1), 139-147.

Kania, N., Kartimi, \& Mulyani, A. (2013). Penerapan Pembelajaran Biologi Berbasis Sains Lokal Melalui Budaya Paraji Terhadap Hasil Belajar Siswa Pada Pokok Bahasan Sistem Reproduksi Kelas XI di SMA Negeri Jatiwangi. Jurnal Scientiae Educatia, 2(2), 1-18.

Muzakki, \& Fauziah, P. Y. (2015). Implementasi Pembelajaran Anak Usia Dini Berbasis Budaya Lokal di PAUD Full Day School. Jurnal Pendidikan Dan Pemberdayaan Masyarakat, 2(1), 39-54.

Puspadewi, K. R., \& Gst. Ngurah Nila Putra, I. (2014). Etnomatematika di Balik Kerajinan Anyaman Bali. Jurnal Matematika, 4(2), 80-89.

Qolbi, F., Kartimi, \& Roviati, E. (2016). Penerapan Pembelajaran Berbasis Sains Budaya Lokal Ngarot Untuk Meningkatkan Keterampilan Berfikir Kritis Siswa Pada Konsep Plantare. Jurnal Sains Dan Pendidikan Sains, 5(2), 105-121.

Rosa, M., \& Orey, D. C. (2011). Ethnomathematics: The Cultural Aspects Of Mathematics. Revista Latinoamericana de Etnomatematica, 4(2), 32-54.

Sariyatun. (2013). Pengembangan Model Pendidikan Nilai-Nilai Budaya di SMP Berbasis Tradisi Seni Batik Klasik Surakarta. Paramita, 23(2), 230-241.

Supriadi, Arisetyawan, A., \& Tiurlina. (2016). Mengintegrasikan Pembelajaran Matematika Berbasis Budaya Banten Pada Pendirian SD Laboratorium UPI Kampus Serang. Mimbar Sekolah Dasar, 3(1), 1-18.

Tanu, I. K. (2016). Pembelajaran Berbasis Budaya Dalam Meningkatkan Mutu Pendidikan di Sekolah. Jurnal Penjamin Mutu, 2(1), 34-43. 